\title{
Valorization of the essential oil of Zingiber officinale by its Use as inhibitor against the corrosion of the carbon steel in acid medium hydrochloric acid $1 \mathrm{M}$
}

\author{
Kelthoum Tarfaoui ${ }^{1,4}$, Moussa Ouakki ${ }^{2}$, Mouhsine Galai ${ }^{3, *}$, Marieme Nehiri ${ }^{1}$, Mohamed Ebn Touhami ${ }^{3}$, \\ Najiba Barhada ${ }^{4}$ and Mohammed Ouhssine ${ }^{1}$ \\ ${ }^{1}$ Laboratoire d'Agro-physiologie, Biotechnologie, Environnement et Qualité \\ ${ }^{2}$ Laboratoire Matériaux, Electrochimie et Environnement \\ ${ }^{3}$ Laboratoire d'Ingénierie des Matériaux et d'Environnement : Modélisation et Application \\ ${ }^{4}$ Laboratoire de Biodiversité et Ressources Naturelle \\ Faculty of Science, Ibn Tofail University BP. 133-14000, Kénitra, Morocco
}

\begin{abstract}
In this work, we are interested in the study of the protection of ordinary steel in acid medium $(\mathrm{HCl})$ $1 \mathrm{M}$ by adding Zingiber officinale EO rhizomes essential oil at different concentrations: $0.5 \mathrm{~g} / \mathrm{L}, 1 \mathrm{~g} / \mathrm{L}, 1.5 \mathrm{~g} / \mathrm{L}$ and $2 \mathrm{~g} / \mathrm{L}$.

The technique used is an electrochemical technique based on the recording of intensity-potential curves in potentio-kinetic mode. The inhibitory action exerted by the essential oil is revealed by tracing the transient curves of the impedance $\mathrm{Z}$ to determine in a first step the percentage of inhibition and the stationary curve in order to confirm the first result.

The main results have shown that the essential oil of ginger (Zingiber officinale) can slow down or inhibit corrosion in acid medium (hydrochloric acid), steel. The maximum percentage inhibition is $96 \%$. It should be noted that it is obtained with the concentration $1.5 \mathrm{~g} / \mathrm{L}$ of essential oil.
\end{abstract}

Keywords: Zingiber officinale EO; corrosion; inhibition; hydrochloric acid; carbon steel; electrochemical technique.

\section{Introduction}

Corrosion affects most industrial sectors and can cause huge losses. In the case of industrial processes, metals are exposed to the action of acids used in chemical processes and during cleaning in several industries. These acids cause the degradation of metals, either by chemical or electrochemical reactions. The best way to protect these materials against corrosion is through the use of inhibitors ${ }^{1,2}$. This use, even in small concentrations has a significant decrease in the percentage of corrosion on the surface of the metal ${ }^{3,4}$.

Although these inhibitors exhibit good anticorrosion action, most of them are highly toxic to humans and the environment, hence the importance of converging towards less harmful, natural and biodegradable inhibitors. Recently several studies have been conducted in this direction, using the plants especially their essential oil as inhibitors ${ }^{5}$.

One of the widely used metals in industry, particularly for structural applications is carbon steel but being susceptible to rust in humid air and high dissolution in acidic media, its wider use becomes an obstacle ${ }^{6}$. For the cleaning and stripping of steel structures; hydrochloric acid and sulfuric acid, are generally used in industrial processes but are normally accompanied by considerable dissolution of the metal ${ }^{7}$.

This work aims to evaluate the inhibitory efficacy of the essential oil Zingiber officinale oil on Carbon steel in a 1.0 $M$ solution of $\mathrm{HCl}$ through the exploitation of potentiodynamic polarization curves, the impedance spectroscopic. The effect of temperature on corrosion is also studied in a range from $298 \mathrm{~K}$ to $328 \mathrm{~K}$. 
The thermodynamic parameters, such as $\Delta H a$ enthalpy and $\underline{\Delta \mathrm{Sa}}$ entropy, were calculated and analyzed.

\section{Materiel and Methods}

\section{Materiel}

The tested materiel in this study is carbon steel with the chemical composition listed in Table 1:

Table 1. Chemical composition of the used carbon steel.

\begin{tabular}{|c|c|c|c|c|c|c|c|c|c|c|c|c|}
\hline Eléments & $\mathrm{C}$ & $\mathrm{Si}$ & $\mathrm{Mn}$ & $\mathrm{Cr}$ & $\mathrm{Mo}$ & $\mathrm{Ni}$ & $\mathrm{Al}$ & $\mathrm{Co}$ & $\mathrm{Cu}$ & $\mathrm{V}$ & $\mathrm{W}$ & $\mathrm{Fe}$ \\
\hline \hline teneur \% & 0.11 & 0.24 & 0.47 & 0.12 & 0.02 & 0.1 & 0.03 & $<0.0012$ & 0.14 & $<0.003$ & 0.06 & 98.7 \\
\hline
\end{tabular}

The used carbon steel specimens have a rectangular form with $4 \mathrm{~cm} \times 1 \mathrm{~cm} \times 0.25 \mathrm{~cm}$. The specimen's surface was prepared by polishing it with emery paper at different grit sizes (from 180 to 1200), rinsing with distilled water, degreasing with ethanol, and drying it at hot air. The aggressive solution of $1 \mathrm{M} \mathrm{HCl}$ was prepared by dilution of analytical grade $37 \% \mathrm{HCl}$ with distilled water.

\section{Extraction of the essential oil}

The essential oil extracted from the rhizomes of Zingiber officinale has a complex composition since it consists of a mixture of compounds that belong to different classes of organic chemistry. The composition of the same species can vary according to the geographical location, the climatic conditions, the period of harvest, the part of the plant used and the drying method. The properties can also vary, hence the need to work in the same conditions, to have the reproducibility of the results at the stage of analysis and identification of the molecules contained in the oil. The essential oil was extracted from the rhizomes of Zingiber officinale by the "Clevenger" hydrodistillation technique ${ }^{8}$. The apparatus consists of a round-bottomed flask, in which are placed the material containing the volatile oil and a given quantity of water; a separator, in which the oil is automatically separated from the distillate in a graduated tube, thereby permitting a direct reading of the quantity of the oil; and a convenient condenser ${ }^{9}$. The collected oil was kept in an opaque bottle at $4^{\circ} \mathrm{C}$.

\section{Electrochemical tests}

Electrochemical experiments have been performed using a Potentiostat Radiometer Analytical type PGZ 100 to positive direction using Volta Master 4 software which was controlled by a personal computer coupled with an electrochemical cell containing three-electrode cell: a platinum as counter electrode (CE), a carbon steel as a working electrode (with an exposed surface of $1 \mathrm{~cm}^{2}$ ), and saturated calomel electrode (SCE) as the reference electrode. All potentials were measured against this later electrode. The potentiodynamic polarization curves were recorded by changing the electrode potential automatically from negative to positive values versus $E_{\text {corr }}$ at a scan rate of $1 \mathrm{mV} / \mathrm{s}$ after $30 \mathrm{~min}$ of immersion time until reaching steady state. The test solution was thermostatically controlled at $298 \pm 2 \mathrm{~K}$ using $50 \mathrm{ml}$ of test solution.

In order evaluate corrosion kinetic parameters, a fitting by Stern-Geary equation was used. Thus, the overall current density values, $i$ were considered as the sum of two contributions, anodic and cathodic current $i_{a}$ and $i_{c}$, respectively. For the potential domain not too far from the open circuit potential, it may be considered that both processes followed the Tafel law ${ }^{10}$. Thus, it can be derived from equation (1):

$i=i_{a}+i_{c}=i_{\text {corr }}\left\{e^{\left[b_{a}\left(E-E_{\text {corr }}\right)\right]}-e^{\left[b_{c}\left(E-E_{\text {corr }}\right)\right]}\right\}(1)$

Where $\mathrm{i}_{\text {corr }}$ is the corrosion current density $\left(A \mathrm{~cm}^{-2}\right), \mathrm{b}_{\mathrm{a}}$ and $\mathrm{b}_{\mathrm{c}}$ are the Tafel constants of anodic and cathodic reactions $\left(V^{-1}\right)$, respectively. These constants are linked to the Tafel slopes $\beta(V / d e c)$ in usual logarithmic scale given by equation (2):

$\beta=\ln 10 /_{b}=2.303 / b$

The corrosion parameters were then evaluated using nonlinear least square method by applying the previous equation using Origin software. However, for this calculation, the potential range applied was limited to $\pm 0.100 \mathrm{mV} / \mathrm{ECS}$ around $\mathrm{E}_{\mathrm{corr}}$, and a significant systematic divergence was sometimes observed for both anodic and cathodic branches.

The corrosion inhibition efficiency $\left(\boldsymbol{\eta}_{p p} \%\right)$ is evaluated from the corrosion current densities values using the following equation (3) ${ }^{11}$ :

$\boldsymbol{\eta}_{p p} \%=\left[\left(\boldsymbol{i}_{\text {corr }}^{\circ}-\boldsymbol{i}_{\text {corr }}\right) / i_{\text {corr }}^{\circ}\right] \times 100$

Where $i_{\text {corr }}^{0}$ and $i_{\text {corr }}$ are the corrosion current densities in absence and presence of the inhibitor, respectively

EIS measurements performed at corrosion potentials, $\mathrm{E}_{\text {corr }}$, over a frequency range of $100 \mathrm{kHz}$ to $100 \mathrm{MHz}$ with an AC signal amplitude perturbation of $10 \mathrm{mV}$ peak to peak. The EIS diagrams were done in the Nyquist plot. The results were then analyzed in terms of an equivalent electrical circuit using Brockamp program $^{12}$.

The inhibition efficiency $\left(\eta_{\text {imp } \%}\right)$, is calculated using equation (4):

$\eta_{\text {imp }} \%=\left(R_{C T}-R_{C T}^{\circ} / R_{C T}\right) \times 100$

$\theta=R_{C T}-R_{C T}^{\circ} / R_{C T}$ 
Where $\mathrm{R}_{\mathrm{ct}}^{0}$ and $\mathrm{R}_{\mathrm{ct}}$ are the charge transfer resistance in absence and presence of the inhibitor, respectively, $\theta$ is the recovery rate.

\section{Result and discussion}

\section{Chemical composition}

The analysis of the essential oil of ginger by chromatography in the gaseous stage coupled by a spectre of mass enabled us to identify eighteen compounds (Table 2). The most abundant components are: Geranial (23.30\%), Camphene $(12.59 \%)$ Eucalyptol $(12.87 \%)$, and alpha-Zingiber ne $(7.38 \%)$.

Table 2. Chemical Composition of Zingiber officinal essential oil.

\begin{tabular}{|c|c|c|c|}
\hline $\operatorname{Tr}$ & aire & $\%$ & Nom \\
\hline 3.866 & 767203 & 3.06 & alpha.-Pinene \\
\hline 4.256 & 3154656 & 12.59 & Camphene \\
\hline 4.791 & 360472 & 1.44 & beta.-Myrcene \\
\hline 5.541 & 1029433 & 4.11 & D-Limonene \\
\hline 5.690 & 1995171 & 7.96 & beta.-Phellandrene \\
\hline 5.836 & 3225554 & 12.87 & Eucalyptol \\
\hline 6.958 & 614769 & 2.45 & beta.-Linalool \\
\hline 8.618 & 299462 & 1.19 & Borneol \\
\hline 8.938 & 1180579 & 4.71 & alpha.-Terpineol \\
\hline 10.032 & 296378 & 1.18 & Dodecan-2-one \\
\hline 10.291 & 3299622 & 23.30 & Geranial \\
\hline 12.643 & 1848341 & 7.38 & alpha.-Zingiber ne \\
\hline 12.780 & 356637 & 1.42 & beta.-Bisabolene \\
\hline 12.926 & 274817 & 1.10 & .beta.-Himachalene \\
\hline 13.108 & 568711 & 2.27 & .beta.-Sesquiphellandrene \\
\hline 13.700 & 306697 & 1.22 & trans-Nerolidol \\
\hline 13.869 & 471674 & 1.88 & Elemol \\
\hline 14.570 & 393856 & 1.57 & alpha.-Bisabolol \\
\hline
\end{tabular}

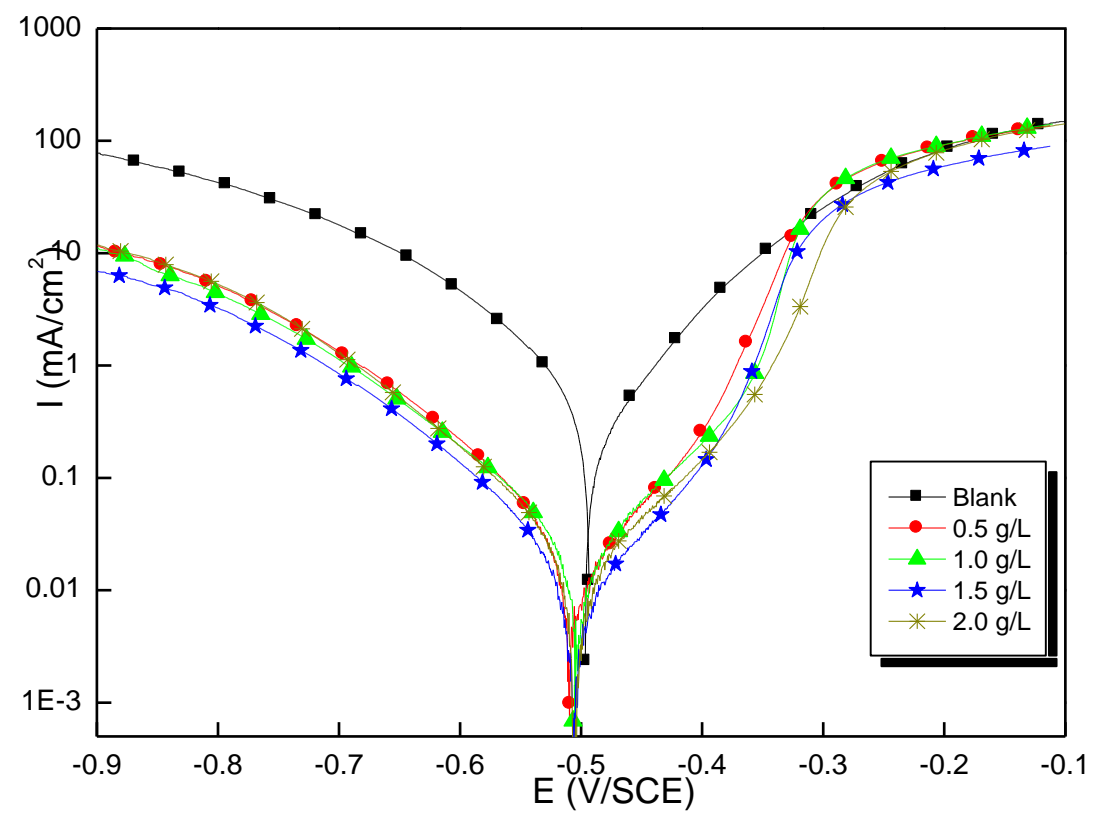

Figure 1. Polarization curves of carbon steel in $1 \mathrm{M} \mathrm{HCl}$ with and without Zingiber officinale EO at various concentrations at $298 \mathrm{~K}$ 


\section{Electrochemical studies}

\section{Polarization studies}

Figure 1 represents the cathodic and anodic polarization curves of carbon steel, in $1 \mathrm{M} \mathrm{HCl}$, with and without inhibitor at different concentrations, the electrochemical parameters: anodic Tafel constancy $(\beta a)$, cathodic Tafel constancy $(\beta c)$, corrosion potential $\left(E_{\text {corr }}\right)$ and the corrosion current density $\left(i_{\text {corr }}\right)$ and inhibition efficiency $\left(\eta_{p p} \%\right)$ are given in Table 3.

It is clear from Fig. 1 that the addition of the Zingiber officinale EO reduces both the cathodic and the anodic currents and therefore hinders the acid attack of the carbon steel electrode in $1 \mathrm{M} \mathrm{HCl}$. The significant change of Tafel slopes of the anodic $(\beta a)$ and cathodic $(\beta c)$ in the presence of Zingiber officinale EO can be observed as a result of adsorption the molecules of inhibitor. The corrosion process decrease can be explained by both metallic dissolution and hydrogen evolution at the metal surface due to the adsorption of an organic compound (heteroatom such as oxygen) ${ }^{13,14,15}$.

Based on these results, the Zingiber officinale EO can be considered as mixed type inhibitor in $1 \mathrm{M} \mathrm{HCl}$. From Table 3 , it is clear that the $i_{\text {corr }}$ values decrease considerably with the increase of the concentration of Zingiber officinale EO. That means that the inhibitory actions are due to their adsorption on the carbon steel surface. Accordingly, $\left(\eta_{p p} \%\right)$ values increase with increasing the inhibitor concentration reaching a maximum value of $97.4 \%$ with $1.5 \mathrm{~g} / \mathrm{L}$ of ginger oil.

Table 3. Polarization data of carbon steel in $1.0 \mathrm{M} \mathrm{HCl}$ without and with Zingiber officinale EO at $298 \mathrm{~K}$.

\begin{tabular}{|c|c|c|c|c|c|c|}
\hline Compound & $\begin{array}{c}\text { Conc. } \\
\mathrm{g} / \mathrm{L}\end{array}$ & $\begin{array}{c}-\mathrm{E}_{\text {corr }} \\
\mathrm{mV} / \mathrm{SCE}\end{array}$ & $\begin{array}{c}\mathrm{i}_{\text {corr }} \\
\mu \mathrm{A} \mathrm{cm}^{-2}\end{array}$ & $\begin{array}{c}-\beta_{\mathrm{c}} \\
\mathrm{mV} \mathrm{dec}^{-1}\end{array}$ & $\begin{array}{c}\beta_{\mathrm{a}} \\
\mathrm{mV} \mathrm{dec}^{-1}\end{array}$ & $\begin{array}{c}\eta_{\text {PP }} \\
\%\end{array}$ \\
\hline \multirow{2}{*}{$\mathrm{HCl} 1.0 \mathrm{M}$} & -- & 498 & 983 & 140 & 150 & - \\
\hline \multirow{3}{*}{ EO } & 0.5 & 506 & 42 & 127 & 67 & 95,7 \\
\cline { 2 - 7 } & 1.0 & 498 & 39 & 128 & 92 & 96,0 \\
\cline { 2 - 7 } & 1.5 & 504 & 25 & 125 & 77 & 97,4 \\
\cline { 2 - 7 } & 2.0 & 503 & 30 & 119 & 83 & 96,9 \\
\hline
\end{tabular}

\section{EIS studies}

The corrosion behavior of mild steel in $1.0 \mathrm{M} \mathrm{HCl}$ with and without Zingiber officinale EO is also investigated by EIS at corrosion potential. The nyquist plot, for carbon steel in $1.0 \mathrm{M} \mathrm{HCl}$ with Zingiber officinale EO at $298 \mathrm{~K}$, is shown in Figure 2. The Nyquist spectra exhibit a single capacitive loop single wave attributed to charge transfer of the corrosion process ${ }^{16}$. These Nyquist plots are not perfect semicircles, and this may be attributed to the frequency dispersion of interfacial impedance ${ }^{17}$.
This behavior is a result of the surface roughness, the chemical heterogeneity of surface, and the adsorption-desorption process of inhibitive molecules on carbon steel surface ${ }^{18}$. Furthermore, the diameter of the semicircles in the presence of Zingiber officinale EO is larger than observed in blank solution $(1.0 \mathrm{M} \mathrm{HCl})$ and increases with increasing inhibitor concentration, which may be related to the increase of surface coverage of inhibitive molecules on the carbon steel surface.

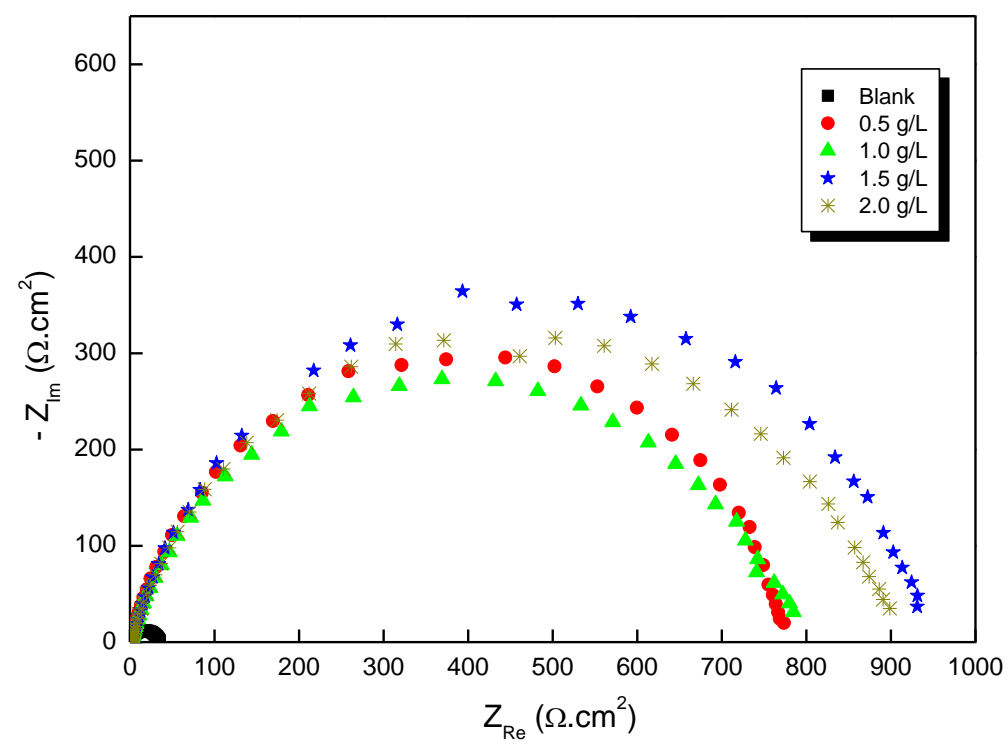

Figure 2. Impedance plots for steel interface in 1.0M HCl medium, presented in Nyquist plan, absence and presence of different concentrations of Zingiber officinale EO at $298 \mathrm{~K}$ 
Accordingly, the simple electrical equivalent circuit (Figure 3) has been proposed to model the experimental data. The employed circuit allowed the identification of the solution resistance (Rs) and charge transfer resistance $\left(\mathrm{R}_{\mathrm{ct}}\right)$. It is noteworthy that the double layer capacitance $\left(\mathrm{C}_{\mathrm{dl}}\right)$ value was affected by imperfections of the surface, and this effect was simulated via a constant phase element $(\mathrm{CPE}){ }^{19}$. CPE was used as the substitute for the capacitor to fit more accurately impedance behavior of the electric double layer. The impedance of the CPE is expressed as ${ }^{20}$ :

$Z_{C P E}=\mathrm{Y}^{-1}(\mathrm{j} \omega)^{n}$

Where $\mathrm{Y}$ is the magnitude of the CPE; $\omega$ the angular frequency; $\mathrm{n}$ is an empirical exponent which measures the deviation from the ideal capacitive behavior ${ }^{21}$. Depending on the values of $n, C P E$ can represent resistance $(n=0)$, capacitance $(n=1)$, inductance $(\mathrm{n}=-1)$ and Warburg impedance $(\mathrm{n}=0.5)^{22,23}$. Also, the double layer capacitances, $\mathrm{Cdl}$, for a circuit including a CPE were calculated by using the equation (6) ${ }^{24}$ :

$\mathrm{C}_{\mathrm{dl}}=\mathrm{Q}\left(\omega_{\max }\right)^{\mathrm{n}-1}$

Where $\omega_{\max }=2 \pi \mathrm{f}_{\max }$ is the angular frequency at the maximum value of the imaginary part of the impedance spectrum, $\mathrm{Q}$ is the constant phase element (CPE).

The impedance spectrums were fitted, and their parameters were calculated according to different models and listed in Table 4.

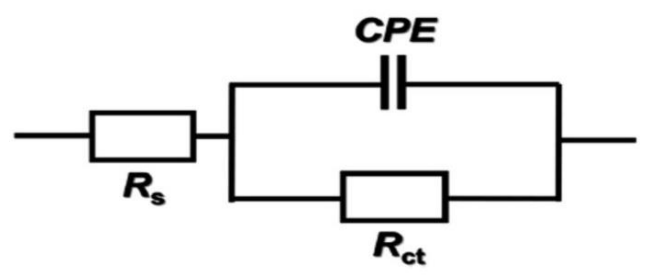

Figure 3. The electrochemical equivalent circuit used to fit the impedance spectra

Inspection of the results in Table 4 indicated that $R_{c t}$ value increased and $\mathrm{C}_{\mathrm{dl}}$ decreases with the increased concentration of the inhibitor. This is attributed to the increase in surface coverage of carbon steel by inhibitor molecule leading to enhanced inhibition efficiency ${ }^{25}$. The increase in $R_{c t}$ value is attributed to the formation of a protective film on the metal/solution interface. The impedance study also gave the same efficiency trend as found in Tafel polarization method.

Table 4. Electrochemical impedance parameters of carbon steel in $1 M \mathrm{HCl}$ medium in the absence and the presence of the inhibitor at different concentrations at $298 \mathrm{~K}$.

\begin{tabular}{|c|c|c|c|c|c|c|c|c|}
\hline Medium & $\mathrm{C}(\mathrm{g} / \mathrm{L})$ & $\begin{array}{c}\mathrm{R}_{\mathrm{s}} \\
\left(\Omega \mathrm{cm}^{2}\right)\end{array}$ & $\begin{array}{c}\mathrm{R}_{\mathrm{ct}} \\
\left(\Omega \mathrm{cm}^{2}\right)\end{array}$ & $\begin{array}{c}\mathrm{C}_{\mathrm{dl}} \\
\left(\mu \mathrm{F} \mathrm{cm}^{-2}\right)\end{array}$ & $\mathrm{n}_{\mathrm{dl}}$ & $\begin{array}{c}\mathrm{Q} \\
\left(\mu \mathrm{F} . \mathrm{S}^{\mathrm{n}-1}\right)\end{array}$ & $\begin{array}{c}\boldsymbol{\Theta} \\
\eta_{\mathrm{imp}} \\
\%\end{array}$ \\
\hline \multirow{3}{*}{$\mathrm{HCl}$} & -- & 1.12 & 34.7 & 121.0 & 0.773 & 419 & - & - \\
\hline \multirow{3}{*}{ EO } & 0.5 & 2.87 & 774 & 41.96 & 0.856 & 68.55 & 0.955 & 95,5 \\
\cline { 2 - 10 } & 1.0 & 1.43 & 779.8 & 55.67 & 0.804 & 102.7 & 0.956 & 95,6 \\
\cline { 2 - 10 } & 1.5 & 1.31 & 951.8 & 68.62 & 0.806 & 116.5 & 0.964 & 96,4 \\
\cline { 2 - 9 } & 2.0 & 0.84 & 902 & 46.34 & 0.795 & 88.7 & 0.962 & 96,2 \\
\hline
\end{tabular}
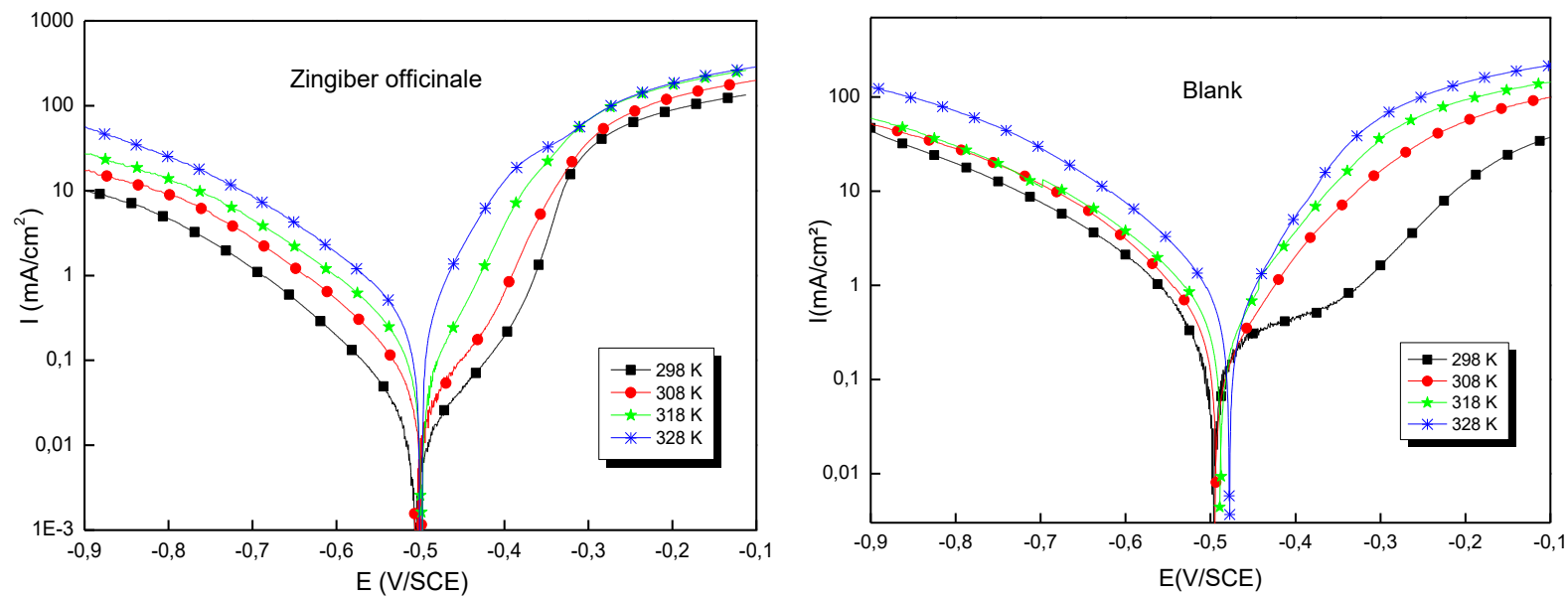

Figure 4. Temperature effect in $1.0 \mathrm{M} \mathrm{HCl}$, with $1.5 \mathrm{~g} / \mathrm{L}$ of Zingiber officinale EO and uninhibited solution 


\section{Effect of temperature}

In order to get more information about the adsorption type of Zingiber officinale EO and its effectiveness at higher temperatures, potentiodynamic polarization measurements were used in the temperatures range from 298 to $328 \mathrm{~K}$ for carbon steel electrode in $1.0 \mathrm{M} \mathrm{HCl}$ without and with $1.5 \mathrm{~g} / \mathrm{L}$ of Zingiber officinale EO after $30 \mathrm{mn}$ of immersion time (Figure 4). It is remarked that these curves exhibited the Tafel regions. It is also noted that the anodic and cathodic branches increased with the increase of temperature.

The values of corrosion current density ( $\left.i_{\text {corr }}\right)$, Corrosion potential of steel $\left(\mathrm{E}_{\mathrm{corr}}\right)$, and the inhibitory efficiency of both inhibitors as a function of temperature are given in Table 5.

Table 5. Influence of temperature on electrochemical parameters of steel in $1.0 \mathrm{M} \mathrm{HCl}$ without and with addition of $1.5 \mathrm{~g} / \mathrm{L}$ of Zingiber officinale EO.

\begin{tabular}{|c|c|c|c|c|c|c|}
\hline Compound & $\begin{array}{c}\text { Temperature } \\
\mathrm{K}\end{array}$ & $\begin{array}{c}-\mathrm{E}_{\text {corr }} \\
\mathrm{mV} / \mathrm{SCE}\end{array}$ & $\begin{array}{c}\mathrm{i}_{\text {corr }} \\
\mu \mathrm{A} \mathrm{cm}^{-2}\end{array}$ & $\begin{array}{c}-\beta_{\mathrm{c}} \\
\mathrm{mV} \mathrm{dec}^{-1}\end{array}$ & $\begin{array}{c}\beta_{\mathrm{a}} \\
\mathrm{mV} \mathrm{dec}^{-1}\end{array}$ & $\begin{array}{c}\eta_{\mathrm{PP}} \\
\%\end{array}$ \\
\hline \multirow{3}{*}{ Blank } & 298 & 498 & 983 & 140 & 150 & - \\
\cline { 2 - 7 } & 308 & 491 & 1200 & 184 & 112 & - \\
\cline { 2 - 7 } & 318 & 475 & 1450 & 171 & 124 & - \\
\cline { 2 - 7 } & 328 & 465 & 2200 & 161 & 118 & 97,4 \\
\hline \multirow{5}{*}{ inh } & 298 & 504 & 25 & 125 & 53 & 94,1 \\
\cline { 2 - 7 } & 308 & 497 & 71 & 135 & 75 & 90,9 \\
\cline { 2 - 7 } & 318 & 496 & 131 & 145 & 83 & 87,7 \\
\hline
\end{tabular}

It can be seen that the $i_{\text {corr }}$ increased with increased temperature, both in uninhibited and inhibited solutions, and the values of the inhibition efficiency of Zingiber officinale EO decreased with higher temperatures. Thus, the inhibition efficiencies of Zingiber officinale EO are temperature-dependent.

\section{Activation parameters of corrosion process}

The activation thermodynamic parameters of the corrosion process can be determined using Arrhenius Eq. and Eq. transition state ${ }^{26}$ :

$\ln \mathrm{i}_{\text {corr }}=\ln \mathrm{A}-\frac{\mathrm{Ea}}{\mathrm{RT}}$

$\ln \frac{\text { icorr }}{\mathrm{T}}=\left(\ln \left(\frac{\mathrm{R}}{\mathrm{Nh}}\right)+\frac{\Delta \mathrm{Sa}}{\mathrm{R}}\right)-\frac{\Delta \mathrm{Ha}}{\mathrm{RT}}$

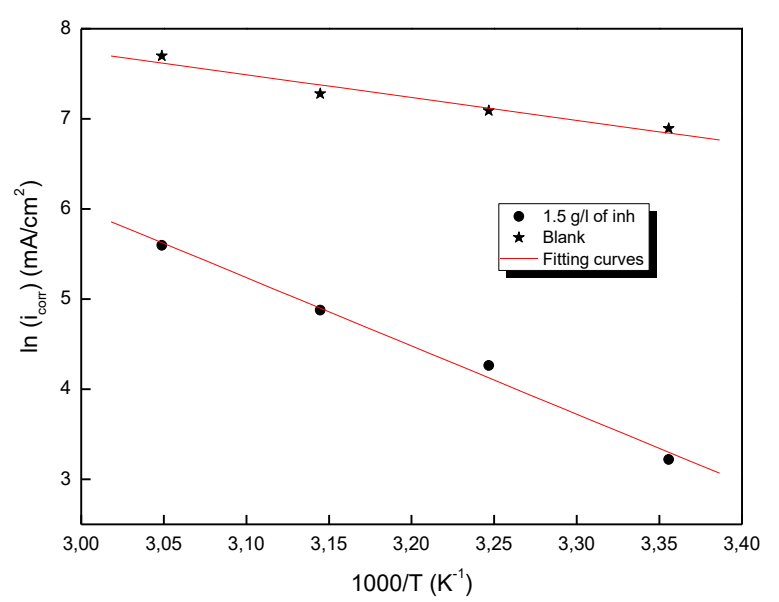

Where Ea is the apparent activation energy, $\mathrm{R}$ is the gas constant; $\mathrm{A}$ is the Arrhenius pre-exponential factor, $\mathrm{N}$ is Avogadro's number, $\mathrm{h}$ is Plank's constant, $\Delta \mathrm{Sa}$ is the entropy of activation and $\Delta \mathrm{Ha}$ is the enthalpy of activation.

A plot of $\ln \left(\mathrm{i}_{\text {corr }}\right)$ vs $1000 / \mathrm{T}$ obtained gave a straight line with regression coefficient close to unity, as shown in Figure 5. The Arrhenius plot of $\ln \left(\mathrm{i}_{\text {corr }} / \mathrm{T}\right)$ vs 1000/T (Figure 5) which gave straight lines with slope $\Delta \mathrm{Ha} / \mathrm{R}$ and intercept $(\ln (\mathrm{R} / \mathrm{N} . \mathrm{h})+\Delta \mathrm{Sa} / \mathrm{R})$ from which $\Delta \mathrm{Ha}$ and $\Delta \mathrm{Sa}$ values were calculated. The values of $\Delta \mathrm{Ha}$ and $\Delta \mathrm{Sa}$ were calculated and listed in Table 6.

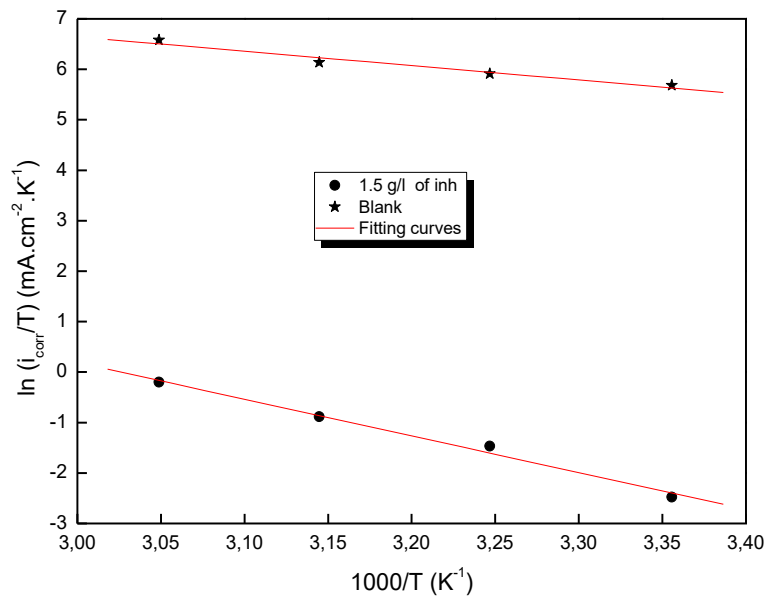

Figure 5. Arrhenius curves of carbon steel in $1 \mathrm{M} \mathrm{HCl}$ with and without $1.5 \mathrm{~g} / \mathrm{L}$ of essential oil of Zingiber officinale 
Table 6. The value of the activation parameters Ea, $\Delta \mathrm{Ha}$ and $\Delta \mathrm{Sa}$ of carbon steel in $1 \mathrm{M} \mathrm{HCl}$ in the absence and in the presence of $1.5 \mathrm{~g} / \mathrm{L}$ of essential oil of Zingiber officinale

\begin{tabular}{|c|c|c|c|}
\hline & $\mathrm{Ea}(\mathrm{KJ} / \mathrm{mol})$ & $\Delta \mathrm{Ha}(\mathrm{KJ} / \mathrm{mol})$ & $\Delta \mathrm{Sa}(\mathrm{KJ} / \mathrm{mol} . \mathrm{K})$ \\
\hline Blank & 21 & 18.5 & -126 \\
\hline $1.5 \mathrm{~g} / \mathrm{L}$ of inh & 63 & 60.4 & -14.7 \\
\hline
\end{tabular}

It was observed that the value of apparent activation energy Ea are higher in the presence of inhibitor than in its absence. This result indicated that the energy barrier for the corrosion reaction increases in the presence of inhibitor is associated with physical adsorption or weak chemical bonding between the inhibitor specie and the steel surface ${ }^{27,28}$ The positive values of $\Delta \mathrm{Ha}$ mean that the dissolution reaction is an endothermic process indicating difficulty of carbon steel dissolution ${ }^{29,30}$. The entropy $\Delta \mathrm{Sa}$ increases negatively in the presence of Zingiber officinale EO which reflects that the activated complex represents an association rather than a dissociation step which means the formation of an ordered, stable layer of this inhibitors on the carbon steel surface ${ }^{31,32}$.

\section{Conclusion}

The following conclusions can be derived from the study of Corrosion inhibition characteristics of Zingiber officinale EO on carbon steel corrosion in $1 \mathrm{M} \mathrm{HCl}$ medium:

$\checkmark$ The Zingiber officinale EO are efficient corrosion inhibitor for carbon steel in the studied medium.

$\checkmark$ Polarization measurement showed the Zingiber officinale EO are mixed type inhibitor.

$\checkmark$ Electrochemical impedance results show that the obtained Nyquist diagrams exhibit one single capacitive loop, indicating that carbon steel corrosion in essentially under charge transfer control, leading to the formation of a protective layer on the metal surface, which limits the steel corrosion.

$\checkmark$ The study of the influence of temperature on the inhibitory efficiency shows that this is decreasing with increasing temperature. That confirms that the Zingiber officinale EO adsorption on the steel surface is done by physisorption type.

$\checkmark$ Reasonably good agreement was observed between the obtained measures from potentiodynamic polarization curves and electrochemical impedance spectroscopy techniques.

\section{References}

1- C.C. Nathan and A.J. Piluso, "It takes knowhow to combat wet-end corrosion problems in paper mills", Paper Trade Journal, 1977, 161 (22), 32-35.
2- $\quad$ M. Benabdellah, M. Benkaddour, B. Hammouti, M. Bendahhou, A. Aouniti, Appl. Surf. Sci., 2006 252, 6212-6217.

3- P.R. Roberge, Handbook of Corrosion Engineering, McGraw-Hill, New York, 2000.

4- Cristofari et al., Chemical Composition and Anti-Corrosive Activity of Pulicaria Mauritanica Essential Oil Against the Corrosion of Mild Steel in $0.5 \mathrm{M} \mathrm{H}_{2} \mathrm{SO}_{4}$ International Journal of Electrochemical Science, 2011, 6, 6699-6717.

5- V.E. Tyler, The honest herbal, a sensible guide to the use of herbs and related remedies. New York: Pharmaceutical Products Press .2002, 375.

6- S. Bilgic, N. Caliskan, J. Appl. Electrochem., 2001, 31, 79.

7- L.R. Chauhan, G. Gunasekaran, Corros. Sci., 2007, 49, 1143.

8- M. Stern, and A. L. Geary, J. Electrochem. Soc., 1957, 104, 56.

9- J. F. Clevenger J. Pharmaceutical Sci ,1928, 17(4), 345-349.

10- M. Ouakki, M. Galai, M. Cherkaoui, El. Rifi, Z. Hatim. Bioanal. Electrochem 2018, 10(7), 943-960.

11- A. Bouckamp, User's Manual Equivalent Circuit, 1993, 4, 51.

12- K. Alaoui, Y. El Kacimi, M. Galai, K. Dahmani, R. Touir, A. El Harfi, M. EbnTouhami, Anal. Bioanal.Electrochem. 2016, 8, 830.

13- C. Gabrielli, M. Keddam, and H. Takenouti, Matériaux and Techniques 2007, 95, 385.

14- L. Kadiri, M. Galai, M. Ouakki, Y. Essaadaoui, A. Ouass, M. Cherkaoui, E. Rifi and A. Lebkiri. Coriandrum Sativum. L Seeds Extract as a Novel Green Corrosion Inhibitor for Mild Steel in 1.0 M Hydrochloric and 0.5 M Sulfuric Solutions, Anal. Bioanal. Electrochem. 2018, 10(2), 249-268.

15- M. Galai, M. Rbaa, Y. El Kacimi, M. Ouakki, N. Dkhirech, R. Touir, B. Lakhrissi, and M. EbnTouhami, Anal. Bioanal. Electrochem., 2017, 9, 80.

16- M. Galai, M El Gouri, O. Dagdag, Y. El Kacimi, A. Elharfi, M. Ebn Touhami M, New hexa propylene glycol cyclotiphosphazene as efficient organic inhibitor of carbon steel corrosion in hydrochloric acid medium. J Mater Environ Sci, 2016, 7, 1562.

17- M. Ehteshamzadeh, AH. Jafari, E. Naderi, M.G. Hosseini, Effect of carbon steel 
microstructures and molecular structure of two new Schiff base compounds on inhibition performance in $1 \mathrm{M} \mathrm{HCl}$ solution by EIS. Mater Chem Phys, 2009, 113, 986-993.

18- C. B. Verma, M. J. Reddy, and M. A. Quraishi, Anal. Bioanal. Electrochem., 2014, 6, 321.

19- M. Ouakki, M. Rbaa, M. Galai, B. Lakhrissi, E. H. Rifi, M. Cherkaoui, Experimental and Quantum Chemical Investigation of Imidazole Derivatives as Corrosion Inhibitors on Mild Steel in 1.0 M Hydrochloric Acid, Journal of Bio- and Tribo-Corrosion 2018, 4, 35.

20- D. A. Lopez, S. N. Simison, and S. R. de Sanchez, Electrochim. Acta, 2003, 48, 845.

21- X. Zheng, S. Zhang, W. Li, L. Yin, J. He, and J. Wua, Corros. Sci., $2014,80,383$.

22- M. Hosseini, S.F.L. Mertens, M. Ghorbani, M.R. Arshadi, Asymmetrical Schiff bases as inhibitors of mild steel corrosion in sulphuric acid media. Mater Chem Phys, 2003, 78, 800-808.

23- M.A. Hegazy, M. Abdallah, M.K. Awad, M. Rezk, Three novel di-quaternary ammonium salts as corrosion inhibitors for API X65 steel pipeline in acidic solution: part I: experimental results. Corros Sci, 2014, 81, 54-64.

24- A. K. Singh, and M. A. Quraishi, J. Appl. Chem ,2010, 40, 1293.

25- K. Bouhrira, F. Ouahiba, D. Zerouali et al. E-J. Chem., 2010, 7, 35.

26- N. Gharda, M. Galai, L. Saqalli, M. Ouakki, N. Habbadi, R. Ghailane, A. Souizi, M. Ebn Touhami, Y. Peres-lucchese, Synthesis, Structural Properties and Complex Corrosion
Inhibition Cu (II) With Amino Acid (DL-aAlanine). Oriental Journal of Chemistry, 2017, 33, 1665-1676.

27- K. Dahmani, M. Galai, M. Cherkaoui, A. El hasnaoui, A. El Hessni, J. Materials and environmental sciences, 2017, 8, 16761689.

28- M. El Faydy, M. Galai, M. Rbaa, M. Ouakki, B. Lakhrissi, M. Ebn Touhami and Y. El Kacimi, Synthesis and Application of New Quinoline as Hydrochloric Acid Corrosion Inhibitor of Carbon Steel, Anal. Bioanal. Electrochem., Vol. 10, No. 7, 2018, 815-839.

29- F. Bentiss, M. Lebrini, M. Lagrenee, M. Traisnel, A. Elfarouk, H. Vezin, Electrochim. Acta, The influence of some new 2,5disubstituted 1,3,4-thiadiazoles on the corrosion behaviour of mild steel in $1 \mathrm{M} \mathrm{HCl}$ solution: AC impedance study and theoretical approach, Electrochimica Acta, 2007, 52, 6865-6872 (2007) [doi: 10.1016/j.electacta.2007.04.111]

30- N. Dkhireche, M. Galai, Y. El Kacimi, M. Rbaa, M. Ouakki, B. Lakhrissi, M. Ebn Touhami, New Quinoline Derivatives as Sulfuric Acid Inhibitor's for Mild Steel, Anal. Bioanal. Electrochem., 2018, 10(1), 111-135.

31- M. Rbaa, M. Galai, Y. El Kacimi, M. Ouakki, R. Touir, B. Lakhrissi, M. Ebn Touhami, Adsorption Properties and Inhibition of Carbon Steel Corrosion in a Hydrochloric Solution by 2-(4,5-diphenyl-4,5-dihydro-1h-imidazol-2-yl)5-methoxyphenol Portugaliae Electrochimica Acta, 2017, 35(6), 323-338. 